\title{
Influência do tempo de aclimatação na resposta do cajueiro à salinidade
}

\author{
Jean C. A. Brilhante1, Joaquim A. G. Silveira1, Iza M. A. Rocha1, Déborah L. de Morais² \& Ricardo A. Viégas ${ }^{2}$
}

\section{RESUMO}

A resposta das plantas à salinidade depende de fatores fisiológicos, bioquímicos e genéticos. Com este trabalho, objetivouse estudar o impacto do tempo de aclimatação à solução nutritiva sobre a resposta do cajueiro à salinidade. Plantas de Anarcadium occidentale L., CCP06, cultivadas em vermiculita durante 28 dias, foram transferidas para solução nutritiva de Hoagland com 1/10 de sua força iônica, onde permaneceram por 1 e 7 dias. Ao final dos dois tempos, a solução nutritiva foi suplementada com $200 \mathrm{mM}$ de $\mathrm{NaCl}$, condições em que as plantas foram cultivadas por 0, 12, 24, 48 e $72 \mathrm{~h}$. As plantas aclimatadas por 7 dias á solução de Hoagland apresentaram sinais fisiológicos mais compatíveis com a tolerância ao $\mathrm{NaCl}$, como menor acumulação de $\mathrm{Na}^{+}$e, também, menores danos nas membranas, peroxidação dos lipídeos, degradação de proteínas, acumulação de aminoácidos livres e acumulação de prolina. A amônia livre foi o melhor indicador da intensidade do estresse salino. Os danos de membranas aumentaram com a acumulação de $\mathrm{Na}^{+}$nas folhas. Os resultados evidenciam que 0 tempo de aclimatação das raízes à solução nutritiva influencia a expressão de fatores capazes de atenuar os efeitos do estresse salino.

Palavras-chave: Anarcadium occidentale L., estresse salino, $\mathrm{Na}^{+}$, prolina, aminoácidos

\section{Influence of acclimatization time on response of cashew plant to salinity}

\begin{abstract}
The plant response to salinity depends on physiological, biochemical and genetic factors and on their interaction with external environment. This work aimed to study the impact of adaptation time in nutrient solution on the cashew response to salinity. Seedlings of Anacardium occidentale L (CCP06) grown in vermiculite, for 28 days, were placed to grow in 1/10 ionic strength Hoagland solution for 1 and 7 days. At the end of each time the solution was supplemented with $200 \mathrm{mM} \mathrm{NaCl}$, and under this condition the plants were monitored for $0,12,24,48$ and $72 \mathrm{~h}$. The 7 days Hoagland solution acclimated plants had physiological index more compatible to tolerance to $\mathrm{NaCl}$ such as low $\mathrm{Na}^{+}$accumulation and also low membrane damage, lipid peroxidation, protein degradation and free amino acids and proline accumulation. The free ammonia was the best index to predict the salt stress intensity. Membrane damage increased with $\mathrm{Na}^{+}$accumulation in the leaves. The results evidence that the root adaptation time in Hoagland solution has influence on the expression of factors capable to alleviate the salt stress effects.
\end{abstract}

Key words: Anarcadium occidentale L., salinity stress, $\mathrm{Na}^{+}$, proline, amino acids 


\section{INTRODUÇÃO}

A salinização dos solos é um dos grandes problemas enfrentados não só nas regiões áridas e semi-áridas do Nordeste brasileiro mas, também, em muitas outras regiões do mundo, em razão, principalmente da intensa evapotranspiração, baixas precipitações e irrigação (Silveira et al., 2001). A maioria das espécies vegetais submetidas à salinidade tem o crescimento reduzido afetando sobremaneira sua produtividade, sobretudo devido aos efeitos osmóticos e de toxicidade por íons salinos (Niu et al., 1995). As conseqüências desses estresses, isoladamente ou em conjunto, ocorrem na planta, tanto nos níveis fisiológico e bioquímico (Munns, 2002) como a nível molecular (Winicov, 1998).

As estratégias adaptativas elaboradas pelas plantas para superar a salinidade, buscam limitar os efeitos dos fatores de estresse e ocorrem em diversos níveis de organização. Os mecanismos complexos para resistência ao estresse iônico e osmótico, provocados pelo estresse salino, incluem: (a) ajustamento osmótico e proteção de estruturas sub-celulares, através da acumulação de solutos compatíveis, como a glicina, betaína, prolina e polióis (Bohnert et al., 1999); (b) manutenção da "homoeostasis" iônica intracelular, através da manutenção de alta relação $\mathrm{K}^{+} / \mathrm{Na}^{+}$citosólica, seqüestro de íons tóxicos para o vacúolo ou extrusão celular (Zhu, 2003) e (c) eliminação de radicais reativos de oxigênio oriundos do estresse oxidativo o qual é desencadeado pela salinidade (Cavalcanti et al., 2004).

A tolerância ao estresse salino é um caráter genético quantitativo que envolve diversos genes (Winicov, 1998). É provável que a tolerância à salinidade envolva adaptações nas membranas que afetam a permeabilidade e facilitam o transporte de íons, porém a resposta das plantas à salinidade depende de vários fatores, como o estádio fisiológico no qual é imposto o estresse, a sua duração e intensidade, as condições ambientais externas e, principalmente, o genótipo utilizado (Silveira et al., 2001). É universalmente aceito que as plantas estão constantemente sofrendo a ação de fatores de estresse, os quais podem desencadear cascatas de respostas bioquímicas capazes de atenuar aqueles ou outros tipos de estresse ambiental, fenômenos denominados resposta cruzada (Zhu \& Xiong, 2002).

Apesar da cajucultura ser praticada intensivamente na faixa litorânea do Nordeste brasileiro e em regiões de clima semiárido, conseqüentemente em áreas sujeitas às condições de salinização dos solos, os trabalhos sobre os efeitos da salinidade com relação à produtividade e às respostas fisiológicas desta cultura ao estresse salino são ainda escassos, em especial no campo da fisiologia (Viégas et al., 2001; Silveira et al., 2003). Trabalho recente realizado na Universidade Federal do Ceará demonstrou que plantas de cajueiro são capazes de sobreviver a dosagens elevadas de $\mathrm{NaCl}(200 \mathrm{mM})$, em hidroponia, durante 14 dias, e que existe grande variação fenotípica entre diferentes genótipos (Silva, 2004). Outros estudos mostram que o estresse salino em plantas jovens de cajueiro produz alterações bioquímicas e fisiológicas significativas, especialmente reduzindo os conteúdos de $\mathrm{K}^{+}$das raízes (Meneses, 2002) e diminuindo a relação $\mathrm{K}^{+} / \mathrm{Na}^{+}$(Vié- gas et al., 2003), aumento da proteólise (Silveira et al., 2003), redução na atividade de redutase do nitrato (Viégas et al., 1999; Matos et al., 2003), acumulação de grandes quantidades de prolina nas folhas (Silveira et al., 2000; Viégas et al., 1999; Rocha, 2003), acumulação de amônia livre (Viégas \& Silveira, 1999) e redução na condutância estomática (Silva, 2004).

Observações recentes têm mostrado que a resposta apresentada por plantas de cajueiro frente a dosagens elevadas de $\mathrm{NaCl}$ não tem sido uniforme, mesmo quando cultivadas em ambiente controlado por curta duração (dias). Aparentemente, mudanças em algum fator ambiental (temperatura, umidade relativa, luminosidade, tempo de adaptação ao substrato etc.) durante a fase de pré-aclimatação poderiam estar influenciando as respostas ao estresse salino. Uma possível explicação para as diferenças de resposta ao $\mathrm{NaCl}$ poderia ser o fato de que o Anacardium occidentale L. possui grande plasticidade fenotípica frente ao estresse salino; na verdade, este fator é encontrado freqüentemente em algumas espécies vegetais dificultando, em muito, a interpretação dos resultados obtidos (Munns, 2002).

Os mecanismos de respostas os quais envolvem a expressão coordenada de genes e atividade de proteínas, são muito pouco conhecidos (Flowers, 2004). O esclarecimento de tais mecanismos contribuiria muito para a compreensão dos resultados aparentemente conflitantes, publicados na literatura, em termos das respostas ao estresse salino; por exemplo, uma mesma cultivar sob curta exposição ao $\mathrm{NaCl}$ pode responder como "excluidora" de $\mathrm{Na}^{+}$e, inversamente, como "incluidora" durante exposição por longo tempo. Em adição, uma mesma cultivar pode apresentar resposta diferenciada quando comparada com outra da mesma espécie, dependendo do tipo de estratégia experimental adotada: dosagem de $\mathrm{NaCl}$, tipo de substrato, tempo de exposição e estádio fisiológico (Munns, 2002).

Realizou-se este trabalho visando testar a hipótese de que o tempo de pré-aclimatação (adaptação) das raízes de plantas de cajueiro à solução nutritiva, produz modificações na resposta ao estresse salino, através de mudanças em indicadores fisiológicos freqüentemente associados à sensibilidade e/ ou resistência a esta forma de estresse ambiental.

\section{MATERIAL E MÉTODOS}

\section{Material vegetal e condições de crescimento das plântulas}

Sementes da progênie de cajueiro anão precoce (Anacardium occidentale L.) CCP06 fornecidas pela EMBRAPA CNPAT, Fortaleza, CE, foram esterilizadas superficialmente com solução comercial de hipoclorito de sódio 10\% (volume), durante 10 min e, em seguida, lavadas exaustivamente com água destilada e deixadas em embebição, com aeração contínua, durante 24 h. Para germinação utilizou-se, como substrato, vermiculita agrícola expandida com capacidade média de retenção de água de 70\% (na base de volume). A fase de germinação e desenvolvimento das mudas foi conduzida em condições de casa de vegetação, situada no Campus do Pici, 
Fortaleza, Ceará, Brasil (latitude $3^{\circ} 44^{\prime} \mathrm{S}$, longitude $38^{\circ} 33^{\prime} \mathrm{W}$ ). As médias de temperatura e umidade relativa do ar foram de $28,1^{\circ} \mathrm{C}( \pm 5,4)$ e $69,8 \%( \pm 18,9)$, respectivamente, com fotoperíodo médio de $12 \mathrm{~h}$ e radiação fotossinteticamente ativa máxima de aproximadamente $550 \mu \mathrm{mol} \mathrm{m}^{-2} \mathrm{~s}^{-1}$ (às 12:00 h). O experimento foi conduzido de março a abril de 2002.

As plântulas, divididas em 2 grupos, foram irrigadas em dias alternados, com água destilada até os 28 (grupo 1) e 34 (grupo 2) dias após a germinação (plantas com 6 folhas completamente expandidas). Nesses dias, as plantas foram transferidas para vasos de $800 \mathrm{~cm}^{3}$ contendo solução nutritiva de Hoagland \& Arnon (1950) modificada, (diluída 1:10), apresentando a seguinte composição: $0,4 \mathrm{mmol} \mathrm{L}-1 \mathrm{KNO}_{3}, 0,3 \mathrm{mmol}$ $\mathrm{L}^{-1} \mathrm{Ca}\left(\mathrm{NO}_{3}\right)_{2}, 0,1 \mathrm{mmol} \mathrm{L}^{-1} \mathrm{CaCl}_{2}, 0,1 \mathrm{mmol} \mathrm{L}^{-1} \mathrm{MgSO}_{4}, 0,1$ mmol.L $\mathrm{L}^{-1} \mathrm{~K}_{2} \mathrm{HPO}_{4}, 0,4$ mmol L-1 $\mathrm{B}^{3+}, 0,09$ mmol L-1 $\mathrm{Mn}^{2+}, 0,18$ mmol L-1 $\mathrm{Cl}^{-}, 0,003 \mathrm{mmol} \mathrm{L}-1 \mathrm{Cu}^{2+}, 0,007 \mathrm{mmol} \mathrm{L}^{-1} \mathrm{Zn}^{2+}$, e 1,0 mmol L ${ }^{-1}$ de $\mathrm{Fe}^{3+}$-EDTA.

\section{Tratamentos e coleta das plântulas}

Estabeleceram-se 2 pré-tratamentos, ou seja: (I) as plantas (grupo 1) foram cultivadas em solução nutritiva continuamente aerada durante 7 dias na casa de vegetação; (II) as plantas (grupo 2) permaneceram na solução nutritiva continuamente aerada durante 1 dia, na casa de vegetação. Após os respectivos períodos de pré-tratamento (I e II) as plantas foram transferidas para a sala de crescimento, em condições controladas de temperatura $\left(24\right.$ a $\left.27^{\circ} \mathrm{C}\right)$, umidade $(70 \%)$, fotoperíodo de $12 \mathrm{~h}$ e radiação fotossintética ativa (PAR) de aproximadamente $230 \mu \mathrm{mol} \mathrm{m} \mathrm{m}^{-2} \mathrm{~s}^{-1}$. As plantas (pré-tratadas por 1 e 7 dias) foram então expostas a $200 \mathrm{mM}$ de $\mathrm{NaCl}$ durante diferentes tempos: 0, 12, 24, 48 e $72 \mathrm{~h}$. Em cada um dos tempos de exposição as plantas foram coletadas individualmente. Na coleta, as folhas foram separadas, imersas em nitrogênio líquido, armazenadas a $-20{ }^{\circ} \mathrm{C}$ e liofilizadas para posteriores análises químicas e bioquímicas.

\section{Determinação da integridade das membranas, peroxidação de lipídeos e concentração de $\mathrm{Na}^{+}$}

A percentagem da integridade das membranas foi estimada pelo vazamento de eletrólitos, segundo Blum \& Ebercon (1981). Para determinação, 10 discos de folhas ( $1 \mathrm{~cm}$ de diâmetro) foram incubados em $20 \mathrm{~mL}$ de água destilada, em tubos de ensaio. O percentual de danos nas membranas (DM) foi estimado pela relação: $\% \mathrm{DM}=(\mathrm{L} 1 / \mathrm{L} 2) \times 100$, em que L1 representa a leitura da condutividade elétrica do extrato, a 25 ${ }^{\circ} \mathrm{C}$, após 24 h de incubação, e L2 a condutividade elétrica do extrato após incubação em banho-maria, a $100^{\circ} \mathrm{C}$, por $1 \mathrm{~h}$, em tubos vedados. O nível de peroxidação de lipídios foi determinado através da formação de substâncias reativas ao ácido tiobarbitúrico (TBA) como descrito por Carmak \& Horst (1991). A concentração das substâncias reativas ao TBA foi calculada utilizando-se o coeficiente de extinção molar de 155 $\mathrm{mM}^{-1} \mathrm{~cm}^{-1}$, após diferença das leituras das absorbâncias em espectrofotômetro a $532 \mathrm{~nm}$ e $660 \mathrm{~nm}$. O Na+ do tecido foi determinado por fotometria de chama, como previamente descrito por (Silveira et al., 2001), após mineralização do tecido foliar em uma mistura de ácido nítrico/perclórico 4/1 em base de volume (Viégas, 1999).
Determinação da concentração de prolina livre, aminoácidos livres totais, amônia livre e proteínas solúveis.

A prolina foi quantificada de acordo com o método de Bates et al. (1973). Os teores deste aminoácido foram estimados com base em uma reta padrão ajustada a partir de concentrações crescentes de L-prolina. A concentração de aminoácidos livres totais foi determinada segundo método descrito por Peoples et al. (1989) e calculada com base em uma reta padrão ajustada a partir de concentrações crescentes de L-glutamina. A amônia livre foi determinada pelo método de Weatherburn (1967) e sua concentração estimada com auxílio de uma reta padrão ajustada a partir de concentrações crescentes de $\left(\mathrm{NH}_{4}\right)_{2} \mathrm{SO}_{4} \mathrm{e}$ as proteínas solúveis foram em conformidade com o método de Bradford (1976) após extração com Tris-HCl 50 mM, pH 7,6. As concentrações de proteínas foram calculadas com base em uma reta padrão ajustada a partir de concentrações crescentes de albumina sérica bovina (BSA).

\section{Delineamento estatístico e análise dos dados}

Os tratamentos foram distribuídos de acordo com o delineamento inteiramente casualizado, obedecendo a um esquema fatorial $(2 \times 5)$ correspondendo, respectivamente, aos tempos de aclimatação das plantas à solução nutritiva ( 1 ou 7 dias de contato) e aos tempos de exposição a $200 \mathrm{mM}$ de $\mathrm{NaCl}(0,12,24,48$ e 72 h), com 4 repetições. Cada repetição consistiu de um vaso individual contendo uma planta. Os dados obtidos foram submetidos a análise de variância e de regressão polinomial.

\section{RESULTADOS E DISCUSSÃO}

\section{Indicadores relacionados com a integridade de membranas e acumulação de $\mathrm{Na}^{+}$em folhas}

De forma geral, as plantas de cajueiro aclimatadas por 7 dias (1 semana) à solução nutritiva, foram bem mais eficientes com o tempo, quando se considerou a sua capacidade de minimizar os efeitos deletérios causados pela alta concentração de $\mathrm{NaCl}$, testada no presente estudo (200 mM); é importante ressaltar que alguns resultados, aparentemente contrastantes com relação à performance de cajueiros em meio salinizado são devidos, aparentemente, não à planta mas, sobretudo, ao tempo de adaptação ao novo substrato a que elas foram submetidas (Viégas, 1999).

Os danos de membrana ajustaram-se à equação quadrática e sua intensidade, estimada através do vazamento de eletrólitos, foi fortemente relacionada aos sintomas visuais de injúrias nas folhas (dados não mostrados); de fato, as plantas aclimatadas por 1 dia apresentaram, com o tempo, aumento consistente nos danos de membrana enquanto nas plantas aclimatadas durante 7 dias os valores permaneceram praticamente inalterados, em todo o período experimental ( 72 h) (Figura 1A); ao final deste período, as plantas aclimatadas por 1 dia apresentaram valores de aproximadamente $43 \%$ contra $20 \%$ (7 dias de aclimatação) de vazamento de eletrólitos. Inesperadamente, os valores de formação do complexo 
MDA-TBA (peroxidação de lipídeos) das folhas das plantas tratadas com $\mathrm{NaCl}$ decresceram ao longo das $72 \mathrm{~h}$ em ambos os tratamentos (Figura 1B); entretanto, nas plantas aclimatadas durante 7 dias, a intensidade da peroxidação (Figura 1B), independente do tempo, ocorreu em menor magnitude, comparativamente com as plantas aclimatadas por 1 dia, corroborando com os resultados anteriores de danos de membrana, avaliados através do vazamento de eletrólitos (Figura 1A).

As plantas aclimatadas por 1 e 7 dias apresentaram acumulação significativa de $\mathrm{Na}^{+}$com o tempo, sendo esta acumulação bem mais expressiva nas plantas aclimatadas por 1 dia (Figura 1C) o que corrobora com os dados de danos de membranas neste tratamento. Ademais, o aumento da concentração de $\mathrm{Na}^{+}$, em função do tempo de exposição foi quadrático, atingindo valores máximos de 450 (aclimatação por 7 dias) e $330 \mathrm{mmol} \mathrm{kg}^{-1} \mathrm{MS}$ (aclimatação por $1 \mathrm{dia}$ ). Curiosamente,

A.

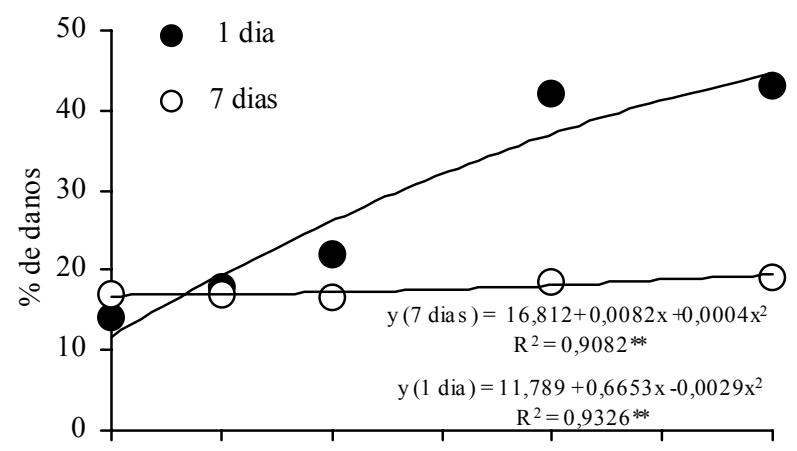

B.

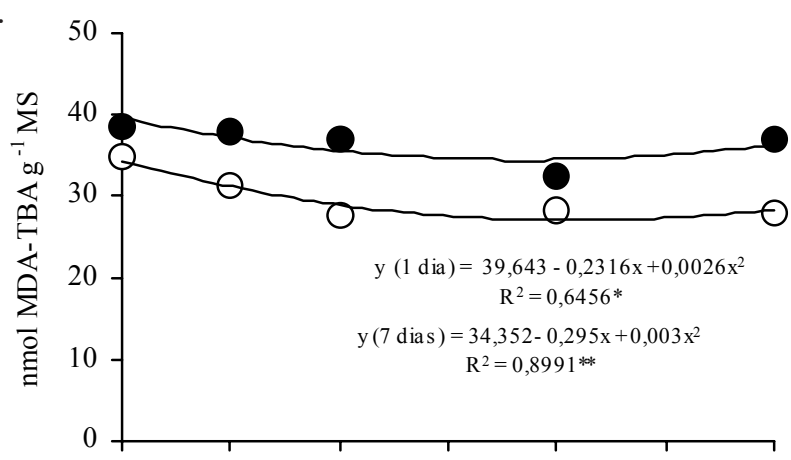

C.

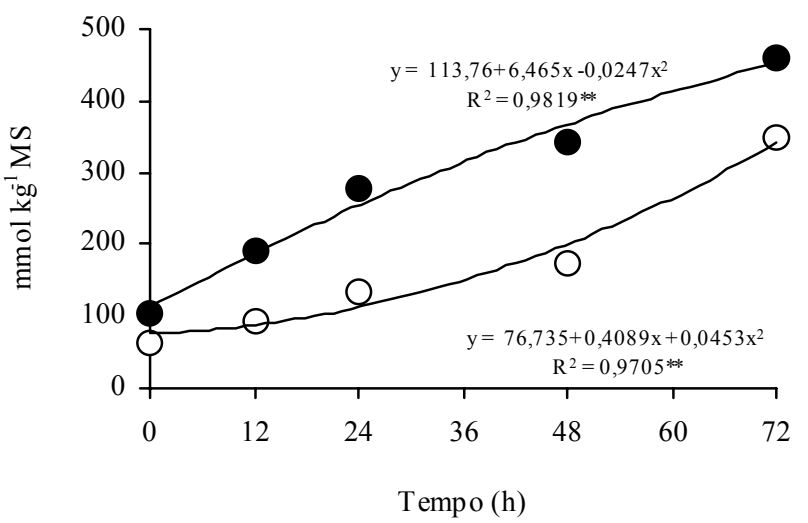

Figura 1. \% de danos nas membranas (A), peroxidação de lipídeos (B) e concentração de $\mathrm{Na}^{+}(\mathrm{C})$ nas folhas de plântulas de cajueiro anão (CCP06) aclimatadas por 1 e 7 dias com subseqüente exposição a $200 \mathrm{Mm}$ de $\mathrm{NaCl}$ por diferentes tempos. ${ }^{* *}$, Significativo a $1 \%$ de probabilidade (Teste F) após $24 \mathrm{~h}$ de exposição à salinidade, as plantas aclimatadas durante 7 dias apresentaram concentração de $\mathrm{Na}^{+}$cerca de 2,5 vezes menor que aquelas aclimatadas por $1 \mathrm{dia}$; em adição, as curvas de acumulação de $\mathrm{Na}^{+}$foram diferentes; as plantas aclimatadas por 7 dias exibiram tendência (fase "leag") de forte exclusão de $\mathrm{Na}^{+}$até 48 horas de exposição (Figura $1 \mathrm{C)}$.

Os resultados do presente estudo indicam claramente que a aclimatação em solução nutritiva durante 7 dias, induz a expressão de fatores em plantas de cajueiro capazes de atenuar os efeitos osmóticos e/ou iônicos do $\mathrm{NaCl}$, em comparação com 1 dia; além disso, os referidos resultados reforçam a idéia de que a resposta das plantas a fatores de estresse abiótico é de natureza extremamente complexa (Munns, 2002). Portanto, a presença de $200 \mathrm{mM}$ de $\mathrm{NaCl}$ (Øos de aproximadamente $0,92 \mathrm{MPa}$ ) causou, inicialmente, um choque osmótico seguido, progressivamente, por um estresse iônico induzido por $\mathrm{Na}^{+}$e $\mathrm{Cl}^{-}$nas raízes de cajueiro (Viégas et al., 2001). A presença de $\mathrm{Na}^{+}$no ambiente radicular pode levar a expressão de diversos genes de resposta ao estresse com aumento na síntese e atividade de proteínas transportadora de membrana e tonoplasto, especialmente os contra-transportadores $\mathrm{Na}^{+} / \mathrm{H}^{+}$, aquaporinas e transportadores seletivos de $\mathrm{K}^{+} / \mathrm{Na}^{+}$ (Zhu, 2003); essas proteínas são essenciais para a manutenção da "homoeostasis" intracelular e absorção de água pelas células.

No caso das plantas de cajueiro aclimatadas durante 7 dias, é possível que este tratamento tenha induzido a expressão de genes favoráveis à aclimatação ao meio salino, caso em que a maior capacidade de exclusão de $\mathrm{Na}^{+}$das folhas pode ter sido relacionada a maior atividade de contra-transportadores de membrana, favorecendo menor influxo de $\mathrm{Na}^{+}$na planta, como tem sido demonstrado em algumas espécies (Zhu \& Xiong, 2002); além disso, a maior expressão de aquaporinas poderia ter favorecido o influxo de água pelas raízes o que, por sua vez, favorece a turgescência. As menores concentrações de $\mathrm{Na}^{+}$nos tecidos foliares poderiam explicar os menores danos nas membranas, quer seja por efeito direto (iônico), quer por efeitos indiretos (osmótico-hídrico), conforme resultados de outros autores (Silva, 2004; Flowers, 2004).

\section{Indicadores de estresse relacionados a distúrbios no metabolismo de aminoácidos}

As concentrações de proteínas solúveis nas folhas das plantas aclimatadas por 7 dias aumentaram significativamente com o tempo de exposição ao estresse salino (Figura 2A); por outro lado, notou-se tendência de redução nas plantas aclimatadas por 1 dia após $19 \mathrm{~h}$ do estresse salino imposto. A variação nas concentrações de aminoácidos livres totais (AALT) mostrou tendência linear de aumento, em função do tempo de exposição nas plantas aclimatadas por 1 dia; além disso, essas plantas apresentaram níveis de AALT cerca de duas vezes superiores que aqueles mostrados pelas plantas aclimatadas por 7 dias (Figura 2B).

As concentrações de prolina nas folhas das plantas aclimatadas por 1 dia aumentaram significativamente com o tempo, atingindo um valor 15 vezes maior, comparado com o tempo inicial. Diferentemente, as plantas aclimatadas por 
A.

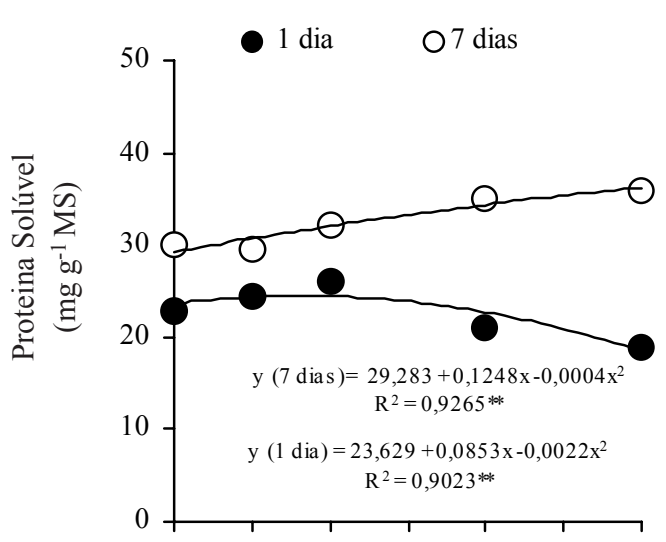

B.

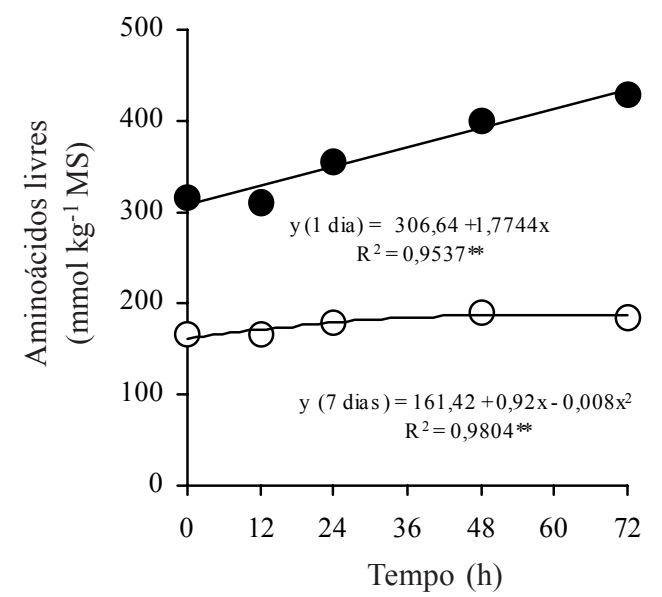

Figura 2. Concentração de proteínas solúveis (A) e aminoácidos livres totais (B) nas folhas de plântulas de cajueiro anão (CCP06) aclimatadas por 1 e 7 dias com subseqüente exposição a $200 \mathrm{Mm}$ de $\mathrm{NaCl}$ por diferentes tempos. ${ }^{* *}$, Significativo a $1 \%$ de probabilidade (Teste $\mathrm{F}$ )

7 dias indicaram aumento mais discreto e mostraram incremento na concentração de prolina de cerca de 2 vezes em relação ao tempo inicial (Figura 3A). É conveniente observar que a acumulação de prolina foi semelhante à acumulação de $\mathrm{Na}^{+}$ nas folhas. $\mathrm{O}$ tratamento com $\mathrm{NaCl}$ provocou rápido e proeminente aumento na concentração de amônia livre das folhas, cerca de 2 vezes, entre 12 e 24 h nas plantas aclimatadas por 1 dia (Figura 3B). Apesar das plantas aclimatadas por 1 dia terem apresentado concentrações mais baixas de amônia até 48 horas, o incremento líquido observado foi maior que nas plantas aclimatadas por 7 dias, resultando em uma acumulação maior no final do período de exposição ao $\mathrm{NaCl}$ (72h).

A degradação proteolítica de proteínas, acompanhada por aumento nas concentrações de aminoácidos e amônia sob condições de estresse salino, tem sido largamente estudada (Viégas \& Silveira, 1999; Yang \& Kao., 2000; Lin \& Kao.,2001; Lin et al., 2002; Brilhante \& Silveira., 2002). Recentemente, comprovou-se que, o aumento nas concentrações de aminoácidos livres e amônia em folhas de cajueiro foi diretamente relacionado com os sintomas de injúrias causados por $\mathrm{NaCl}$ (Silveira et al., 2003; Rocha, 2003; Brilhante, 2003). De maneira semelhante, a acumulação de prolina livre em folhas de cajueiro parece ser meramente um sintoma de injúria causado por distúrbio no metabolismo dos aminoácidos (Viégas, 1999; Viégas et al., 1999; Viégas \& Silveira, 1999; Meneses, 2002;
A.

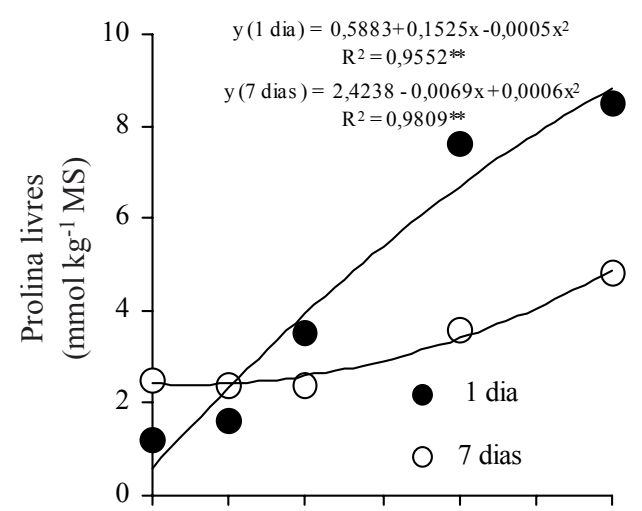

B.

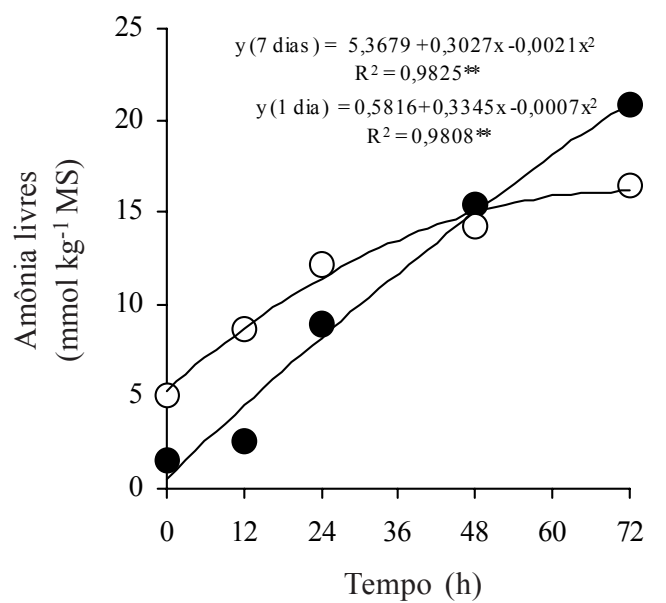

Figura 3. Concentração de prolina livre (A) e amônia livre (B) nas folhas de plântulas de cajueiro anão (CCP06) aclimatadas por 1 e 7 dias com subseqüente exposição a $200 \mathrm{Mm}$ de $\mathrm{NaCl}$ por diferentes tempos. ${ }^{* *}$, Significativo a $1 \%$ de probabilidade (Teste F)

Silveira et al., 2003; Rocha, 2003). Em outras espécies, como o arroz, a mesma origem da prolina parece ocorrer (Lutts et al., 1999).

Os dados apresentados no presente trabalho sugerem, energeticamente, que as plantas aclimatadas durante 7 dias na solução nutritiva adquiriram condição de "endurecimento" (Munns, 2002) suficiente para adequá-las melhor ao estresse salino, comparando-se com as plantas aclimatadas por 1 dia; portanto, através de mecanismos ainda não compreendidos, é provável que o contato das raízes com o meio líquido por um tempo de exposição maior deve atuar na expressão de genes ou fatores de transcrição capazes de promover melhor aclimatação das plantas ao estresse salino. É provável, também, que tais fatores de resposta, provavelmente proteínas, estejam relacionados ao influxo de $\mathrm{Na}^{+}$(contra-transportadores $\mathrm{Na}^{+} / \mathrm{H}^{+}$de plasmalema e/ou tonoplasto) e/ou, com o influxo de água (aquaporinas) e proteínas transportadoras de $\mathrm{Na}^{+} / \mathrm{K}^{+}$(Zhu \& Xiong, 2002; Zhu, 2003; Flowers, 2004).

Os resultados do presente trabalho reforçam a importância dos estudos dos efeitos cruzados e dos mecanismos comuns de resposta a fatores de estresses abióticos, como seca versus salinidade (Maia, 2004) visando compreender os mecanismos de aclimatação e resistência, como forma de estabelecer maneiras de desenvolver manejos capazes de induzir pré-aclimatação como, por exemplo, no preparo de mudas de 
cajueiro mais adaptadas às condições de estresses ambientais.

\section{CONCLUSÕES}

1. A aclimatação das raízes de plantas de cajueiro em solução nutritiva, durante 7 dias, é capaz de promover a expressão de fatores de resposta que possam atenuar os efeitos do estresse salino.

2. Os danos de membrana induzidos por $\mathrm{NaCl}$, nas plantas de cajueiro aclimatadas por 1 dia, não foram decorrentes da peroxidação de lipídeos.

\section{LITERATURA CITADA}

Bates, L.S.; Waldren, R.P.; Teare, I.D. Rapid determination of free proline for water stress studies. Plant and Soil, Dorderecht, v.39, n.1, p.205-209, 1973.

Blum, A.; Ebercon, A. Cell membrane stability as a measure of drought and heat tolerance in wheat. Crop Science, Madison, v.21, n.1, p.43-47, 1981.

Bohnert, H.J.; Su, H.; Shen, B. Molecular mechanisms of salinity tolerance. In: Shinozaki, K., Yamaguchi-Shinozaki, K. (Ed.) Molecular responses to cold, drought, heat and salt stress in higher plants. Austin: University of Arizona, 1999, p.29-62.

Bradford, M.M. A rapid and sensitive method for the quantification of microgram quantities of protein utilizing the principle of protein-dye binding. Analytical Biochememistry, Memphis, v.72, n.1/2, p.248-254, 1976.

Brilhante, J.C.A. Respostas fisiológicas e acumulação de prolina em duas progênies de cajueiro (Anacardium occidentale L.) sob estresse salino. Fortaleza: UFC, 2003. 52p. Monografia Graduação

Brilhante, J.C.A.; Silveira, J.A.G. Proline accumulation related to changes in protein and free amino acid contents in two progenies of cashew expose to salt stress. In: Reunião Anual da Sociedade Brasileira de Bioquímica, 33, 2002, Caxambu. Resumos... Caxambu: SBB, 2002. p.47.

Carmak, I.; Horst, W.J. Effects of aluminum on lipid peroxidation, superoxide dismutase, catalase, and peroxidase activities in root tips of soybean (Glicine max). Physilogia Plantarum, Copenhagen, v.83, n.3, p.463-468, 1991.

Cavalcanti, F.B.; Oliveira, J.T.A.; Miranda, A.S.M.; Viégas, R.A.; Silveira, J.A.G. Superoxide dismutase, catalase and peroxidase activities do not confer protection against oxidative damage in salt-stressed cowpea leaves. New Phytologist, Lancaster, v.163, n.3, p.563-571, 2004.

Flowers, T.J. Improving crop salt tolerance. Journal of Experimental Botany, Oxford, v.55, n.396, p.307-319, 2004.

Hoagland, D.R.; Arnon, D.I. The water cultured method for growing plants without soil. California Agricultural Experiment Station, San Francisco, v.347, p.3-31, 1950.

Lin, C.C.; Hsu, Y.T.; Kao, C.H. The effect of $\mathrm{NaCl}$ on proline accumulation in rice leaves. Plant Growth Regulation, Dordrecht, v.36, n.1, p.275-285, 2002.
Lin, C.C.; Kao, C.H. Regulation of ammonium-induced proline accumulation in detached rice leaves. Plant Growth Regulation, Dordrecht, v.35, n.3, p. 69-74, 2001.

Lutts, S.; Majerus, V.; Kinet, J.M. $\mathrm{NaCl}$ effects on proline metabolism in rice (Oryza sativa) seedlings. Physiologia Plantarum, Copenhagem, v.105, n.4, p.450-458, 1999.

Maia, J.M. Efeitos aditivos e interativos de tratamentos de seca e $\mathrm{NaCl}$ na desposta antioxidativa de raízes de Feijãode-corda (Vigna unguiculata L. Walp.). Fortaleza: UFC, 2004. 126p. Dissertação Mestrado

Matos, N.N.; Teixeira Jr., A.C.; Silveira, J.A.G. Influência do porta-enxerto no comportamento fisiológico de mudas de cajueiro (Anacardium occidentale L.) submetidas a estresses. Revista Brasileira de Fruticultura, Jaboticabal, v.25, n.1, p.27-31, 2003.

Menêses, J. J. Caracteres fisiológicos de progênies de cajueiro expostas ao estresse salino. Fortaleza: UFC, 2002. 132p. Tese Doutorado

Munns, R. Comparative physiology of salt and water stress. Plant Cell and Environment, Logan, v.25, n.2, p.239-250, 2002.

Niu, X.; Bressan, R.A.; Hasegawa, P.M.; Pardo, J.M. Ion homoeostasis in $\mathrm{NaCl}$ stress environments. Plant Physiology, Rockville, v.109, n.5, p.735-742, 1995.

Peoples, M.B.; Faizah, A.W.; Reakasem, B.; Herridge, D.F. Methods for evaluating nitrogen fixation by nodulated legumes in the field. Canberra: Australian Center for International Agricultural Research, 1989. 76p.

Rocha, I.M.A. Regulação metabólica da acumulação de prolina em folhas de cajueiro expostas ao estresse salino. Fortaleza: UFC, 2003.104p. Tese Doutorado

Silva, S.L.F. Transpiração e partição de $\mathrm{Na}^{+}$e $\mathrm{Cl}^{-}$em mudas e porta-enxertos de diferentes genótipos de cajueiro anão precoce submetidos ao estresse salino. Fortaleza: UFC, 2004. 92p. Dissertação Mestrado

Silveira, J.A.G.; Melo, A.R.B.; Viégas, R.A.; Oliveira, J.T.A. Salt-induced effects on the nitrogen assimilation related to growth in cowpea plants. Environmental and Experimental Botany, Memphis, v.46, n.2, p.171-179, 2001.

Silveira, J.A.G.; Viégas, R.A.; Queiroz, J.E. Alterações no metabolismo do nitrogênio e acumulação de prolina em plantas jovens de cajueiro submetidas ao estresse salino. In: Congresso Brasileiro de Fruticultura, 16, 2000, Fortaleza. Resumos... Fortaleza... SBF, 2000, p.251.

Silveira J.A.G.; Viégas R.A.; Rocha, I.M.A.; Monteiro-Moreira, A.C.O.; Moreira, R.M.; Oliveira J.T.A. Proline accumulation and glutamine synthetase are increased by salt-induced proteolysis in cashew leaves. Journal of Plant Physiology, Rockville, v.160, n.2, p.115-123, 2003.

Viégas, R.A. Assimilação de nitrogênio e acumulação de solutos em plantas de cajueiro (Anacardium occidentale L.) em resposta ao estresse salino. Fortaleza: UFC, 1999. 85p. Tese Doutorado

Viégas, R.A.; Melo, A.R.B.; Silveira, J.A.G.. Nitrate reductase activity and proline accumulation in cashew in response to $\mathrm{NaCl}$ salt shock. Brazilian Journal of Plant Phisiology, Campinas, v.11, n.1, p.21-28, 1999. 
Viégas, R.A.; Rocha, I.M.A.; Queiroz, J.E.; Silva, L.M.M.; Silveira, J.A.G.; Viégas, P.R.A. Plant growth, accumulation and solute partitioning of four forest species under salt stress. Revista Brasileira de Engenharia Agrícola e Ambiental, Campina Grande, v.7, n.2, p.258-262, 2003.

Viégas, R.A.; Silveira, J.A.G. Ammonia assimilation and proline accumulation in young cashew plants during long term exposure to $\mathrm{NaCl}$-salinity. Revista Brasileira de Fisiologia Vegetal. Viçosa, v.11, n.3, p.153-159, 1999.

Viégas, R.A.; Silveira, J.A.G.; Melo, A.R.B.; Lima Junior, A.R.; Queiroz, J.E.; Fausto, M.J.M. Effects of NaCl-salinity on growth and inorganic solute accumulation of young cashew plants, Revista Brasileira de Engenharia Agrícola e Ambiental, Campina Grande, v.5, n.2, p.216-222, 2001.
Weatherburn, M.W. Phenol hypochlorite reaction for determination of ammonia. Analytical Biochememistry, Memphis, v.39, n.4, p.971-974, 1967.

Winicov, I. New molecular approaches to improving salt tolerance in crop plants. Annals of Botany, London, v.82, n.6, p.703-710, 1998.

Yang, C.W.; Kao, C.H. Ammonium in relation to proline accumulation in detached rice leaves. Plant Growth Regulation, Dordrecht, v.30, n.2, p.139-144, 2000.

Zhu, J.K. Regulation of ion homeostasis under salt stress. Current Opinion in Plant Biology, London, v.6, n.5, p.441445, 2003.

Zhu, J.K.; Xiong, L. Molecular and genetic aspects of plant responses to osmotic stress. Plant Cell and Environment, Logan, v.25, n. 2, p.131-139, 2002. 